\title{
FIT TO BE CREATIVE: ORGANIZATION-EMPLOYEE CONGRUENCE ON ENVIRONMENTAL VALUES
}

\author{
Jelena Spanjol, University of Illinois at Chicago \\ Leona Tam, University of Wollongong \\ Vivian Tam, University of Western Sydney
}

This study examines how the match (vs. mismatch) between personal and firm-level values regarding environmental responsibility affects employee job satisfaction and creativity and contributes novel insights to three literature streams (i.e., creativity, social corporate responsibility, and person-environment fit). Building on the person-environment (P-E) fit literature, we propose and test environmental orientation fit vs. nonfit effects on creativity, identifying job satisfaction as a mediating mechanism and regulatory pressure as a moderator. An empirical investigation indicates that the various environmental orientation fit conditions affect job satisfaction and creativity differently. More specifically, environmental orientation fit produces greater job satisfaction and creativity when the employee and organization both care highly about the environment (i.e., a high-high environmental orientation fit condition) than when both display congruent low concern for the environmental (i.e., a low-low environmental orientation fit condition). Furthermore, for employees working in organizations that fit with their personal environmental orientation, strong regulatory pressure to comply with environmental standards diminishes the positive fit effect on job satisfaction and creativity, while regulatory pressure does not affect the job satisfaction and creativity of employees whose personal environmental orientation is incongruent with that of the organization.

Reference available upon request 